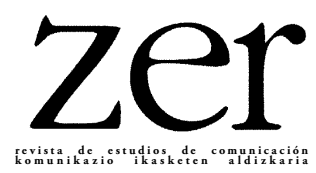

\title{
El racismo discursivo en la prensa escrita: una mirada teórica desde el Análisis Crítico del Discurso y la Sociología de los medios
}

\author{
Arrazismo diskurtsiboa prentsa idatzian: begirada teoriko bat diskurtsoaren \\ analisi kritikotik eta komunikabideen soziologiatik
}

The discursive racism in written press: a theoretical perspective from Critical Discourse Analysis and Media Sociology

\author{
Julio Renato Sáez Gallardo* \\ Doctor UAB
}

\begin{abstract}
RESUMEN: Esta aproximación teórica pretende como objetivo central comprender cómo las rutinas profesionales de los periodistas y de los medios de comunicación condicionan la construcción noticiosa acerca de las minorías étnicas. Para ello, emplearemos el Análisis Crítico del Discurso y la Sociología de los medios y sus correspondientes categorías analíticas como constructos epistemológicos y metodológicos y las vincularemos a investigaciones teórico-empíricas para validar la hipótesis de este trabajo: la praxis racista de la cultura periodística deviene de condicionamientos propios del quehacer de las organizaciones mediáticas, lo que produce un discurso discriminador referente a las minorias étnicas (migrantes y pueblos originarios).
\end{abstract}

PALABRAS clave: Racismo; Prensa; Análisis Crítico del Discurso; Sociología de los medios; Rutinas Periodísticas.

LABURPENA: Gerturatze teoriko honen bidez ulertu nahi da zer neurritan baldintzatzen duten kazetarien eta komunikabideen errutina profesionalek gutxiengo etnikoei buruzko berrien sorkuntza. Horretarako, diskurtsoaren analisi kritikoa eta komunikabideen soziologia baliatuko dira, dagozkion beren kategoria analitikoetan, konstruktu epistemologiko eta metodologiko gisa, eta ikerketa teoriko enpirikoekin lotuko ditugu, azterlan honen hipotesia baliozkotzeko: kazetaritzaren kulturaren praktika arrazista erakunde mediatikoen eginkizunaren berezko baldintzapenen on- 
doriozkoa da, eta horrek gutxiengo etnikoenganako (migratzaileak eta jatorrizko herriak) diskurtso diskriminatzailea sorrarazten $d u$.

HITZ-GAKOAK: Arrazismoa; prentsa; diskurtsoaren analisi kritikoa; komunikabideen soziologia; kazetaritza errutinak.

\begin{abstract}
This theoretical approach aims to understand how the professional work of journalists and press determine the guideline of news about ethnic minority. For this, Critical Discourse Analysis, Media Sociology, and their corresponding analytical categories, like epistemological and methodological constructs, will be applied. These elements will be related with theoretical and empirical investigations to prove the thesis of this paper: the racist praxis of journalism culture comes from the own conditioning of the work of the media organizations, making a discriminatory discourse about ethnic minority (migrants and native people).
\end{abstract}

KEYWORDS: Racism; Press; Critical Discourse Analysis (CDA); Media Sociology; Journalism Culture.

* Correspondencia a: Julio Renato Sáez Gallardo. C/Los Naranjillos, 5.000, Valle Volcanes, ciudad Puerto Montt, Región de Los Lagos, Chile. juliosaez2005@yahoo.es https://orcid.org/0000-0001-9096-3772

Cómo citar: Sáez Gallardo, Julio Renato. 2018. El racismo discursivo en la prensa escrita: una mirada teórica desde el Análisis Crítico del Discurso y la Sociología de los medios. Zer. 23(45). 75-94.

https://doi.org/10.1387/zer.19995

Recibido: 19 junio 2018; aceptado: 15 octubre 2018

1137-1102 y 1989-631X / C 2018 UPV/EHU

(c) (i) Esta obra está bajo una licencia Creative Commons Atribución 4.0 Internacional 


\section{Introducción}

La emergencia de las minorías étnicas debido - por un lado- a las migraciones desde países del Sur hacia Europa dadas las guerras y las crisis político-económicas y - por otro - al resurgimiento de los movimientos reivindicatorios de las culturas aborígenes en América Latina ha originado que la opinión pública y los medios de comunicación la hayan situado como un tema relevante en sus agendas. La aceptación o no de la diversidad cultural por parte de la opinión pública se encuentra condicionada, generalmente, por el rol que juegan los medios masivos de comunicación social, a través de la transmisión y re-creación de imágenes o representaciones sociales de los grupos étnicos minoritarios. En la medida que se ha considerado que la contribución de los medios de comunicación es central para comprender los procesos de normalización del multiculturalismo, diversas investigaciones (Dik, van T., 1994, 1996; Martínez Lirola, 2006, 2008, 2010, 2013) han puesto de manifiesto que aquellos contribuyen al establecimiento de estereotipos si de minorías étnicas se trata.

En razón de la importancia que tienen los medios de comunicación de masas como "constructores de la realidad social» es que nos abocaremos en este trabajo a reflexionar teóricamente desde la sociología de los medios y del conocimiento y el Análisis Crítico del Discurso para respondernos preguntas que intenten esclarecer la construcción de estereotipos y representaciones sociales y su vinculación con la praxis periodistica en un contexto multicultural: ¿por qué obtenemos un tipo de noticia con un marcado carácter racista acerca de minorías étnicas? ¿Cómo influyen las rutinas profesionales de los periodistas y los medios en la construcción de un sesgo racial cuando se trata de minorías étnicas?

Para contestar estas interrogantes nos proponemos como objetivo general comprender cómo las rutinas profesionales de los periodistas y de los medios de comunicación condicionan la construcción noticiosa acerca de las minorías étnicas. Como objetivo específico pretendemos identificar las estrategias del discurso de la noticia que posibiliten reconocer el carácter racista de la cultura profesional periodística.

\section{Metodología e hipótesis}

Este trabajo se inscribe en un paradigma de investigación cualitativo y de corte teórico con sustento en trabajos empíricos. Es de tipo cualitativo por cuanto nos ocuparemos de entender, por una parte, las ideologías predominantes en la construcción de las representaciones sociales referidas a las minorías étnicas y, por otro, la arquitectura de los mensajes periodísticos y su vinculación con la ideología racista y el contexto social, cultural e ideológico para explicar el racismo en las rutinas profesionales de los periodistas. Como método de trabajo ocuparemos la revisión do- 
cumental de textos, tanto teóricos como de investigaciones empíricas. Los criterios de inclusión para la conformación de la muestra están dados por trabajos que aportan sustento epistemológico y analítico desde dos vertientes: en primer lugar, desde el Análisis Crítico del Discurso (ACD) - - su correspondiente categoría analítica como lo es el cuadrado ideológico y sus respectivas aristas (van Dijk, 1999) - y la Sociología de los medios y el uso de instrumentos crítico-analiticos como las teorías de Agenda Setting y la Teoría del framing y, en segundo lugar, ocupamos documentos provenientes de investigaciones empíricas acerca del tratamiento periodístico que se otorga a las minorías étnicas y que utilizan las bases crítico-epistemológicas y las categorías de análisis que ya hemos mencionado (categorías que serán conceptualizadas en el cuerpo del trabajo). Esta medología intenta validar la hipótesis que direcciona esta aproximación: la praxis racista de la cultura periodística deviene de condicionamientos propios del quehacer de las organizaciones mediáticas, lo que produce un discurso discriminador referente a las minorías étnicas (migrantes y pueblos originarios).

\section{Análisis del corpus}

\subsection{El AnÁlisis Crítico del Discurso y los constructos ideológicos SOBRE EL RACISMO Y LA DISCRIMINACIÓN EN LAS CLAVES TEXTUALES PRESENTES EN LA INFORMACIÓN EN PRENSA}

Antes de explicar cómo algunas prácticas periodísticas generan determinados imaginarios sociales que atentan contra las minorías étnicas es razonable proveer un breve contexto teórico y conceptual acerca del racismo como fenómeno político, social y político y su vinculación con las agendas de los medios.

En términos de categoría conceptual, compartimos la aproximación a una noción de racismo propuesta por van Dijk, quien señala que:

[...] el racismo es principalmente un sistema de dominación y de desigualdad social [...] La dominación se define como el abuso de poder de un grupo sobre otro, y está representada por dos sistemas interrelacionados de prácticas sociales y sociocognitivas cotidianas, es decir, por varias formas de discriminación, marginación, exclusión o problematización por un lado y por creencias, actitudes e ideologías prejuiciosas y estereotipadas por otro (Dijk, T. van, 2006: 17).

A principios de la década de los ochenta, a nivel teórico, se especula que las formas contemporáneas de racismo se alejan del conocido "viejo» racismo, ese que aplica el concepto de «raza» a los seres humanos y que encuentra sus formas más brutales en la esclavitud, la segregación, o la discriminación sistemática que se funda en la con- 
cepción que las minorías étnicas son biológicamente inferiores. En este debate Graves (2001), el biólogo afroamericano, sostiene que no hay una base de sustentación biológica para la separación de los seres humanos en razas y que la idea de raza es una construcción social y política relativamente reciente, vale decir, una construcción ideológica, para nosotros.

En la actualidad, la argumentación racista se funda ya no en la jerarquía, sino en la «diferencia», ya no en los atributos naturales imputados al grupo "racializado», sino en su cultura, su lengua, su religión, sus tradiciones, sus costumbres (Wieviorka, 2002). Los psicólogos y politólogos norteamericanos acuñaron la noción de «racismo simbólico» para conceptualizar estas formas menos flagrantes de racismo, que pretende ser democrático, respetable y que niega sea racismo. Bajo esta perspectiva, las minorías son «diferentes» y son portadores de «deficiencias», tales como familias monoparentales, carentes de valores de éxito y dependientes de la ayuda social, por lo que no les interesa trabajar para elevarse socialmente. Para van Dijk (2005) es precisamente este "nuevo racismo" (Barker, 1981) el que adopta una forma discursiva, pues se expresa, se promulga en el texto y habla al ser de naturaleza sutil y simbólica.

Por la naturaleza discursiva del racismo actual es que a continuación, reflexionaremos en torno a la importancia que le cabe al discurso periodístico en su reproducción. Por ello, analizaremos las claves textuales y las estrategias discursivas de la prensa que están comprometidas en la formación de modelos mentales y prejuicios racistas inherentes a las prácticas discursivas de los medios de comunicación escritos y que obedecen a una «rutina» instititucionalizada por parte de éstos y otros actores sociales relevantes.

Para ello ocuparemos [...] «la perspectiva del análisis crítico del discurso (ACD), que permite estudiar eficazmente diversas formas de desigualdad social, fijándose, además, en otras dimensiones semióticas y enfocando el rol del discurso hacia el estudio de las relaciones de poder, dominación y desigualdad [...] en beneficio de los más poderosos» (van Dijk, T. 1997:16-17).

Ahora bien, el discurso de carácter ideológico que propala la prensa escrita se asienta en la distinción entre el Nosotros y los Otros y contribuye a la consolidación de una frontera simbólica entre los que se considera como parte de la nación y los que quedan fuera, al margen. La referida escisión determina el tipo de estructuras que ha de tener el discurso. La construcción de la representación social del Otro étnico desde la perspectiva ideológica del Nosotros, grupo dominante, implica la construcción de la propia representación y como dice Walter Mignolo (2004) la exterioridad es la diferencia creada desde la interioridad.

Los trazos en el discurso de la frontera simbólica entre un grupo social y otro es lo que caracteriza al discurso ideológico. El Nosotros representa al grupo con el cual 
el productor del discurso se siente identificado; los Otros, en contraste, representan un "peligro" porque cuestiona lo establecido, tal y como lo hace notar Arrunátegui (2010). El enfrentamiento entre el Nosotros y los Otros en el discurso se manifiesta, según van Dijk (2010) a través de la polarización de las características positivas atribuidas al Nosotros y de las características negativas atribuidas al Otro. Esta polarización de características positivas y negativas constituye, en conjunto, lo que van Dijk (1999) ha denominado el cuadrado ideológico o la estrategia global del discurso ideológico, cuyas aristas corresponden a: 1. Enfatizar lo positivo de Nosotros. 2. Enfatizar lo negativo en los Otros. 3. Desenfatizar los positivo de los Otros y 4. Desenfatizar lo negativo del Nosotros.

En la esfera del racismo y la discriminación subyace esta metaestrategia que enfatiza las dos caras ineluctables del discurso ideológico: la autopresentación presentación positiva del Nosotros (quien detenta el poder simbólico y material) y la presentación negativa del Otro étnico (quien carece de poder simbólico y material). Ello se logra a través de algunas estructuras lingüísticas que típicamente implican creencias ideológicas en determinados contextos de uso. A continuación, pasaremos a revisar las estructuras discursivas que reproducen el cuadrado ideológico y, consecuencialmente, la frontera simbólica entre el Nosotros y los Otros.

En la primera arista del cuadrado ideológico de van Dijk (1999) que consiste en Enfatizar lo positivo del Nosotros, encontramos, según este autor, dos estrategias discursivas que recalcan la imagen positiva de quien produce el discurso y que son susceptibles de ser controladas por éste y que están sujetas a su "poder social», en palabras de Wodak y Meyer (2003), nos referimos a la estrategia intertextual, la estrategia de predicación, agencia y selección léxica. El concepto de intertextualidad hace referencia a la forma en que los textos y los enunciados se construyen sobre la base de textos previos a los que "responden» y estos textos nuevos, constituyen a su vez, la base de textos posteriores (Fairclough, 1992). En otras palabras, la intertextualidad es la «[...] presencia de elementos de otros textos dentro de un texto» (Fairclough, 2003: 39). La relación que existe entre la intertextualidad y las estructuras de poder radica en el modo en que sólo algunos discursos provenientes de fuentes seleccionadas forman parte de la generación de discursos nuevos, mientras que otras fuentes están significativamente ausentes. Es decir, y siguiendo a Fairclough (1992), cuando se construye un discurso, se controla constantemente variables tales como qué se cita, cuándo, cómo, y por qué. Por ello, los discursos que tienen validez son aquellos que generan una imagen favorable del Nosotros. El uso ideológico de la predicación consiste en predicar acciones negativas del Otro y positivas del Nosotros. La agencia, por su parte, complementa la predicación en tanto puede ser utilizada para responsabilizar al Otro de acciones negativas y atribuir al Nosotros acciones positivas, y puede servir también para desenfatizar o mitigar las responsabilidades del Nosotros en acciones negativas, tal y como indica van Dijk (2010). Por su parte, la selección léxica es una estrategia que va de la mano con la agencia y predicación, en la medida 
en que se seleccionan las palabras más «convenientes» que la predicación y la agencia logran construir la imagen positiva del Nosotros.

En la segunda arista del casillero ideológico denominada Enfatizando lo negativo del Otro encontramos las estrategias discursivas de explicitación del grupo étnico, la hiperbolizacion numérica, la estrategia intertextual, y, finalmente, la estrategia de predicación, agencia y selección léxica. Según van Dijk (1999), el discurso racista exhibe un exceso de completitud respecto a la información que ofrece. Vale decir, que hay información innecesaria e irrelevante en el discurso para la comprensión de un acontecimiento. La referida información solo resulta conveniente para el Nosotros porque ayuda a formar una imagen negativa del Otro. Teun van Dijk (1999) ejemplifica esta estrategia al referirse a la narración de un disturbio, en la que se pueden mencionar detalles irrelevantes como el grupo étnico de los participantes: «multitud negra causa disturbio». Según este autor este es un ejemplo paradigmático de cómo se puede establecer la asociación implícita entre un grupo étnico determinado y acciones negativas. En cuanto a la hiperbolizacion numérica van Dijk (2010) denomina a esta estrategia como Number Game, la que consiste en acumular grandes cantidades numérica para relevar la idea de peligro, amenaza o crisis, al mismo tiempo que se intenta demostrar precisión y objetividad en la información transmitida. van Dijk (2010) analiza una noticia en la que el diario inglés The Sun se refiere a los asilos para refugiados extranjeros en el Reino Unido. El autor encuentra que el periódico menciona la existencia de «miles» de asilos en el Reino Unido, un «número que va en aumento» (the rising number), pues se estima que éstos se contaban en «4,223 en 1982 y se han elevado a 110,700 el año pasado» (Dijk, Teun A., 2010:91). Respecto de la estrategia intertextual, así como es utilizada para enfatizar lo positivo del Nosotros a través de la selección de fuentes de información, aquí se utiliza esta misma estrategia para formar una imagen desfavorecedora del Otro, a través del énfasis en sus aspectos negativos. Frecuentemente la prensa usa la estrategia intertextual a favor del Nosotros al seleccionar las voces del Gobierno o los poderosos (terratenientes, partidos políticos, etc.) para construir la noticia enfatizando los aspectos negativos del Otro. Contrariamente, las voces de las minorías étnicas aparecen en menor proporción.

En la arista Desenfatizando lo positivo del Otro, nos encontramos con distintas estrategias discursivas que invisibilizan o mitigan los aspectos positivos del Otro. Este recurso se consigue al cumplirse dos condiciones: a) la información se vincula por medio de conectores de contraste como, pero, aunque o no obstante, los cuales establecen un contraste positivo/negativo y b) la información "positiva» se menciona en primer lugar, lo que genera que ésta quede invisibilizada y la información «negativa» se menciona en segundo lugar, lo cual hace que ésta quede resaltada.

En la arista Desenfatizando lo negativo del Nosotros, se utilizan un conjunto de marcadores modales (como verbos y adverbios) que pueden ser usados ideológi- 
camente para mitigar los aspectos negativos del Nosotros. La modalidad es una categoría gramatical que se relaciona con el grado de "afinidad» del emisor de un enunciado respecto del contenido proposicional de este. La gramática dispone de una serie de recursos lingüísticos que el hablante puede utilizar para expresar cuán «seguro» está de la «verdad» de aquello que está diciendo. Por ejemplo, podemos notar un claro contraste entre las siguientes proposiciones en cuanto a su modalidad: «El gobierno trabaja para la protección de los más débiles de la sociedad» y «Es posible que el gobierno trabaje para la protección de los más débiles de la sociedad». En la primera proposición, la modalidad es categórica, pues el grado de afinidad o certeza es muy alto. En cambio, en el segundo ejemplo, el grado de certeza disminuye notablemente.

Tanto Arrunátegui (2010) en Perú, como Sáez (2015) en Chile, han demostrado que la prensa de sus respectivos países elabora estrategias discursivas para representar negativamente a las minorías étnicas e invisibilizar sus aspectos positivos y, consecuencialmente, presentar positivamente a los Gobiernos e invisibilizar sus características negativas. Es decir, la prensa ha dado forma al cuadrado ideológico, construyendo un discurso racista en donde se denotan claramente relaciones de superioridad/inferioridad entre Nosotros (la élite blanca) y los Otros (la minoría indígena).

\subsection{LA CONSTRUCCIÓN SOCIAL DE LA REALIDAD Y LAS RUTINAS DE PRODUCCIÓN DE LA INFORMACIÓN EN LA REPRESENTACIÓN DEL RACISMO}

Las personas construyen en sociedad sus nociones sobre lo real, sin embargo, desde una perspectiva mediática, las definiciones de la realidad se originan en la trama social. Para Peter Berger y Thomas Luckmann (1972) las reservas de sentido socialmente objetivado y procesado son «mantenidas» en depósitos históricos de sentido y «administradas» por instituciones. La acción del individuo está moldeada por el sentido objetivo proveniente de los acervos sociales de conocimiento y transmitido por las instituciones a través de las presiones que ellas ejercen para su acatamiento. En este proceso, el sentido objetivado mantiene una constante interacción con el sentido construido subjetivamente y con proyectos individuales de acción. Estos autores reconocen que los medios de comunicación, en especial la prensa escrita, han vuelto accesibles para todos las distintas reservas de sentido.

La investigación del papel que juegan los medios de comunicación en la construcción social de la realidad se desarrolla a partir de la segunda mitad del siglo XX. Para algunos autores como Schudson (1989) y Wolf (1987) el origen de los análisis sociológicos de la producción informativa se localiza en los primeros estudios realizados en Estados Unidos acerca de los gatekeepers, mientras que otros autores, en los que se incluyen Hernández (1987), señalan como origen de esta tendencia de investigación la década de los setenta aportando las características distintivas de la socio- 
logía de la producción de noticias y que da cuenta de los factores que intervienen en los procesos de producción de mensajes de los medios de comunicación, especialmente, los de la producción de noticias, línea de trabajo que se centra en el polo emisor de los mensajes y supone el análisis de los medios de comunicación como organizaciones complejas, con una lógica de producción en cierta forma «industrial» (Hernández, 1987).

Para Wolf (1987) este campo de estudio es cercano a los procesos de socialización y como tal se circunscriben en los estudios de la construcción social de la realidad, inmersos en la sociología del conocimiento, en especial desde los aportes de Shütz y Berger y Luckmann.

A nuestro juicio, los estudios sociológicos de los medios implican un enfoque centrado en las condicionantes contextuales en que los medios colaboran en la construcción de lo que llamamos la «realidad» y que, junto a diversos actores sociales, mediante un juego de negociaciones, la crean y re-crean. Los discursos massmediáticos no son los únicos que construyen la realidad social, conviven con otros productores de sentido y en la medida que se transforman en materia significante y circulan en la arena social, son objetos de transacciones, negociaciones, lectura y re-lecturas y potencialmente originan otros discursos, vale decir, que el discurso periodístico como materialidad se inserta en una red de semiosis social, como diría Verón. Precisamente para este autor, desde una perspectiva constructivista, el acontecimiento es construido por los medios.

Convengamos que las definiciones de lo real no son aportadas en forma exclusiva y excluyente por los medios, sino que su aporte a la construcción de la realidad está basado en otros discursos que circulan en el contexto social y que forman parte de esta red productora de sentido.

En las líneas precedentes hemos abordado-desde una mirada de la sociología del conocimiento-someramente cómo los medios de comunicación pueden contribuir a la construcción de significados sociales. Nos interesa a continuación, analizar cómo las rutinas de la labor informativa condicionan en gran medida la producción de la noticia acerca de las representaciones sociales de las minorías étnicas y las implicancias ideológicas que comportan estas prácticas profesionales. Para ello, nos remitiremos al estudio de la modelación del conocimiento $-\mathrm{y}$ por ende de la realidad - que hacen las organizaciones informativas a través de una aproximación teórico-empírica de lo que conocemos en los estudios comunicacionales como Agenda Setting y la Teoría del framing.

Para van Dijk (2005) el papel que juega la prensa en la reproducción del racismo no se limita a la redacción de noticias o editoriales, sino que comienza en las rutinas cotidianas de la producción de noticias: 
Las minorías tienen menos acceso a los medios de comunicación por el hecho de que no controlan las muchas «fuentes de discurso» en las que se basa la producción cotidiana de noticias: ruedas y comunicados de prensa, reuniones y folletos informativos, documentación, entrevistas, etc. Se les preguntan menos sus opiniones o se considera que son menos creíbles o de menor interés periodístico, también porque la mayoría de los periodistas (y prácticamente todos los redactores) son blancos (Dijk, van, T. 2005: 38-39).

Las noticias son un "producto y una predecible construcción de la realidad» (McQuail, 1994: 187), por lo que se infiere que los mensajes mediáticos no son producto de antojos personales, sino de procesos sociales en los que se enmarca la actividad periodística y de la cual es tributaria. En razón de lo señalado, y tal y como indican Hirsch (1977) y Molina (1989), el primer contexto para determinar cómo ocurre la producción de la noticia es el de las normas operativas dentro de los medios de información. En lo que respecta a cuestiones étnicas, es claro que el racismo viene prefigurado por una relación de conveniencias mutuas entre los representantes de las «burocracias informativas» y los de las «burocracias gubernamentales» (Schudson, 1989: 271). Este acceso privilegiado de las elites blancas a los medios de comunicación condiciona el discurso periodístico, en términos de sus estructuras y estrategias, lo que viene a contribuir a la promulgación del racismo. Según van Dijk (2005) las noticias relativas a las minorías étnicas se tematizan negativamente (estrategia general de autopresentación positiva y presentación negativa de los «otros»); los otros étnicos tienen menos posibilidad de ser citados como fuentes informativas y si lo hacen es en compañía de una persona blanca para contradecir lo expuesto por el portavoz de la minoría; se utilizan, por parte de un racismo más simbólico que flagrante, eufemismos y palabras despectivas para referirse a las comunidades étnicas minoritarias.

Como hemos dicho más arriba, las organizaciones informativas modelan el conocimiento social a través de lo que se conoce como el efecto «agenda setting», constructo teórico formulado en la década de los 70 en Estados Unidos por M. McCombs y D. Shaw (1972). Desde esta teoría se analiza cómo los medios ejercen influencia en las audiencias a través de la construcción de la agenda del día, determinando los temas que se consideran importantes para los lectores o telespectadores y que van a encauzar la discusión pública del día:

La Teoría de la agenda-setting ofrece una explicación de por qué la información sobre ciertos argumentos, y otros no, resulta de interés para el público que vive en democracia; cómo se forma opinión pública y por qué determinados temas inducen a adoptar acciones políticas mientras otros carecen de la misma iniciativa. El estudio de la agenda-setting es el estudio de los cambios sociales y de la estabilidad social (Dearing y Rogers, 1996: 2). 
Los medios de comunicación, a través de sus redes de información e influencia, intervienen poniendo orden en el caos que se presenta al tener a disposición una gran cantidad de sucesos que tienen la virtualidad de convertirse en noticia. Los criterios de noticiabilidad pasan por una negociación que se da dentro de un intricado sistema de jerarquías organizacionales y es fruto de los sucesos producidos dentro de una red de noticias que privilegia fundamentalmente los asuntos provenientes de las instituciones sociales, los cuales, a su vez, crean también sus propias oficinas de información para la difusión de los sucesos internos. Los medios de comunicación de masas ofrecen información a los consumidores y refuerzan las otras instituciones sociales ya consolidadas. Se sitúan, en definitiva, en una especie de papel mediador entre el Estado y el pueblo (Montero, 1993).

La teoría de la agenda-setting nos viene a iluminar en este trabajo las relaciones de transferencia de la relevancia temática informativa entre la agenda mediática y la agenda pública. Por ello, concordamos con McCombs y Shaw (1977) que los medios no se limitan a dirigir la atención del público hacia determinados asuntos, sino que, además, presentan estos asuntos de acuerdo con ciertos encuadres interpretativos que contribuyen a seleccionar y enfatizar algunos rasgos o propiedades del objeto en cuestión. Asunto no menor si del tratamiento periodístico de las minorías étnicas se trata, puesto que, desde una óptica del análisis del discurso podemos afirmar que la relevancia del discurso mediático radica en el poder que tienen de darle espacios a determinados actores sociales y sus definiciones del mundo en detrimento de otros actores que son silenciados por su posición de subalternidad en términos sociales, culturales, étnicos, políticos, entre otros.

Muchos son los trabajos empíricos que han abordado esta traslación que se produce desde los asuntos temáticos agendados por los medios hacia la agenda pública (Shaw y McCombs, 1977; Winter y Eyal, 1981; López-Escobar, McCombs y Rey (1996) por lo que el concepto de fijación de agenda tiene bastante aplicabilidad práctica en los estudios comunicacionales. Por ello — dado nuestro foco en el racismo discursivo propalado por los medios - es de nuestro interés referirnos a una investigación empírica que analiza precisamente cómo el periódico El Día (mayor medio de difusión en la Provincia de Santa Cruz de Tenerife, España) ha tratado de marcar la agenda política de Canarias acerca del tema de la inmigración de que es objeto por parte de minorías étnicas africanas. En el trabajo de Rodríguez Borges (2010) se analiza, desde el análisis crítico del discurso y la teoría de agenda-setting, el apoyo prestado el año 2006 por El Día a la manifestación convocada a favor de una ley de residencia para controlar la inmigración. Esta investigación, cuya metodología es cuali-cuantitativa, pretende demostrar la estrategia desplegada por el diario para intentar imponer su discurso en la esfera pública, ejemplo paradigmático que evidencia el poder que ostentan los medios para fijar la agenda de las preocupaciones ciudadanas, inoculando el alarmismo por la inmigración irregular. Se analizó en este estudio las unidades redaccionales que el diario dedicó a la convocatoria de la manifestación, 
se reconstruyó la premeditada secuencia cronológica con que se suministró la información a los lectores y se analizaron los pronunciamientos editoriales del apoyo a la iniciativa. Se concluye que El Día fue capaz de marcar la agenda política de la sociedad y arrastrar tras de sí a los partidos políticos y a las principales instituciones para posicionar su discurso xenófobo.

Siguiendo en la línea de vincular el racismo simbólico de los medios en contra de las minorías étnicas y su inoculación en las agendas públicas, mediante una particular construcción de la realidad, es que avanzamos hacia una teoría del framing o estudio de los encuadres noticiosos para el tratamiento periodístico del tema étnico. Para autores como McCombs, López-Escobar y Llamas (2000) los medios de comunicación no sólo marcan sobre qué asuntos pensar o fijan la agenda (primer nivel de la agenda-setting), sino que también influyen en cómo se piensa sobre dichos asuntos (segundo nivel). Se asume que las noticias no son otra cosa que una representación de la realidad hecha por el periodista, lo que va a implicar un determinado enfoque o encuadre (frame), concepto utilizado por diferentes estudiosos de los medios de comunicación y que se debe a Goffman (1974). Tankard (2001) define el encuadre noticioso como «[...] la idea organizativa central del contenido de las noticias, que proporciona un contexto comunicativo y presenta el asunto a través del uso de la selección, énfasis, exclusión y elaboración» (Tankard (2001: 100). En tanto Entman (1993), señala que el proceso de encuadrar significa seleccionar:

[...] algunos aspectos de la realidad percibida, haciéndolos más sobresalientes en el texto comunicativo, de tal manera que consigan promover una definición del problema particular, una interpretación causal, una evaluación moral y/o una recomendación de tratamiento para el asunto descrito (Entman, 1993:52).

Tomando como referencia la teoría del encuadre o framing Igartua y Muñiz (2014) analizan el tratamiento dado por los medios españoles (prensa y televisión) al fenómeno de la representación social de las minorías étnicas inmigrantes en España. Concluyen que existe una especie de correlación ilusoria al asociar inmigración a problemas sociales. Junto a ello, se detectó el uso predominante de los encuadres noticiosos de atribución de responsabilidad, interés humano y conflicto para re-construir la información sobre inmigración.

Respecto a la Teoría del Frame autores como Valera (2016) advierten criticamente que — sobre todo en España - existiría un mediocentrismo por parte de los investigadores, al concebir los encuadres como resultado de las rutinas periodísticas y desatender las múltiples influencias del contexto social y político en la producción de la noticia. 


\subsection{LOS CONTEXTOS DE LA PRODUCCIÓN DE INFORMACIÓN SOBRE EL DISCURSO DEL RACISMO}

Nos proponemos en este apartado reflexionar acerca de los complejos procesos de construcción de la noticia en un marco sociohistórico multicultural, advirtiendo que la producción de ésta es un elemento condicionante a tener en cuenta en el perfilamiento del racismo discursivo generado por los medios de comunicación en contra de las minorías étnicas. Para ello, es necesario que tengamos presente las constataciones epistemológicas que ya hemos señalado más arriba en el sentido de que la noticia forma parte de un complejo proceso productivo: industrial, institucional y rutinario (Tuchman, 1978; Fishman, 1980, Dijk, van, 1990, entre otros); conceptualizándose como una construcción (para la vertiente sociológica constructivista en Berger y Luckman) o una representación (para la psicología social en Moscovici) social de la realidad. Dentro de estas coordenadas epistemológicas cabe precisar que el propósito central de este acápite será, entonces, comprender el proceso de producción noticiosa de la alteridad étnica a través del análisis de las rutinas periodísticas que prefiguran el sesgo racista en detrimento de las minorías étnicas.

Como ya hemos documentado, las investigaciones sobre las rutinas periodísticas y los valores profesionales de los trabajadores de la prensa -elementos que influyen y se reflejan en los contenidos - se han sucedido desde la década del setenta hasta nuestros días. Con mayor vigor, por cierto, en el mundo anglosajón y con escasa investigación empírica desde el continente Sur de América. Para explicar este proceso complejo de producción de la noticia nos centraremos en las perspectivas teóricas sobre producción de medios para indagar a través de ellas cómo las rutinas profesionales, en tanto posibilidades y restricciones, sumadas a ellas los perfiles personales de los periodistas, vienen a incidir en la construcción de la noticia acerca de las minorías étnicas.

Al concebir la noticia como una construcción social de la realidad es inevitable no sustraerse de la subjetividad implícita en los mensajes. Una de las teorías que permite analizar estas problemáticas es la Sociología de la Producción de noticias (Newsmaking) la cual propone estudiar las distintas condicionantes que intervienen en la producción de textos informativos. Como muy bien lo plantea Lozano:

El aspecto central de este enfoque se refiere a que los mensajes de los medios son construidos por los comunicadores, es decir, que no tan solo los seleccionan de la realidad y los transmiten tal cual sino que sus valores profesionales, sus características, las rutinas de trabajo, así como los condicionantes organizacionales, económicos y políticos moldean el contenido de los mensajes y los hacen reflejar visiones parciales y mediatizadas de la realidad (Lozano, 2007: 56). 
En esta misma perspectiva Gaye Tuchman (1978) en su ya clásico texto Producción de la noticia puso en evidencia la estructura latente de la noticia al describir cómo los periodistas deciden qué es noticia y cómo se ocupan de determinados temas y desechan otros y de qué manera deciden lo que el público desea conocer a través los medios. Esta «construcción» o "producción» de la noticia es negada por los periodistas, en consideración a su visión de profesionales «objetivos» que sólo se remiten a reportar, según ellos, hechos que pudieran ser considerados sensacionalistas, discriminadores o racistas, pero en esencia sólo hechos. Sin embargo, como sostiene Sáez (2005), toda construcción del imaginario social impulsada por los media es absolutamente parcial e interesada.

Según White ${ }^{1}$ la noticia es lo altamente subjetivo, lo basado en las propias expectativas, experiencias y actitudes del gatekeeper o guardabarreras. Son éstos - los editores- quienes deciden qué noticias se incluirán en el periódico y cuáles no. Elección más bien cuantitativa, por cuanto el editor decide por sí solo cuáles noticias se van y cuáles se quedan. Rol del editor que estaría asociado al establecimiento de la agenda setting, por cuanto decide qué temas serán los que ocuparán la atención de los receptores de los medios. No obstante lo dicho, también es importante observar a nivel cualitativo de contenidos los diversos tratamientos que los periodistas otorgan a una misma noticia en la que un determinado sesgo cambia la percepción de lo que se informa. Si bien es cierto que los mensajes masmediáticos son frutos de una construcción de significados sociales, no es menos plausible afirmar que estos mensajes son moldeados por una determinada dinámica estructural de los medios de comunicación y los consorcios privados. Sin embargo, en una visión más tradicional se considera que la sociedad proporciona las normas que se reifican para todos los componentes del cuerpo social y que éstas se constituyen en un telón de fondo como estructuras sociales para la construcción de la noticia. Para Tuchman (1978) la estructura social produce normas y actitudes que definen aspectos de la vida social que son de interés o de importancia para los ciudadanos. La autora afirma que:

Se supone que la notica se interesa por estos ítems reconocibles. Socializados en actitudes sociales y en las normas profesionales, los informadores cubren, seleccionan y diseminan relatos acerca de ítems identificados como interesantes o importantes. Mediante el cumplimiento de esta función por los informadores, la noticia refleja la sociedad: la noticia presenta a la sociedad un espejo de sus asuntos e intereses. Para cambiar la definición de la noticia de una sociedad, se infiere lógicamente, tiene que cambiar primero la estructura de la sociedad y sus instituciones (Tuchman, 1978:197).

\footnotetext{
1 Citado por Schudson (1989:272)
} 
No obstante lo planteado por Gaye Tuchman, en este trabajo ponemos el acento en las actividades y rutinas de los periodistas más que en las normas sociales. En esta perspectiva adoptada no es la noticia que refleja la sociedad, sino que ayuda a construirla como fenómeno social compartido. Al concebir la noticia como "producto social», se reconoce que los mensajes mediáticos no son resultados de voluntades individuales, sino de procesos sociales, en los que las organizaciones mediales tienen un lugar preponderante, pues, como Hirsch (1977), Whitney (1982) y Molina (1989) lo plantean, el primer contexto para determinar cómo opera la producción noticiosa es el de las normas operativas dentro de los medios de información.

A nivel de rutinas periodísticas y su vinculación con el racismo discursivo nos interesa, junto con Schudson (1989), reflexionar en cómo los esfuerzos de los periodistas en el trabajo se ven restringidos por rutinas organizacionales y ocupacionales y se torna un problema central la autonomía que supuestamente tienen los periodistas como profesionales y su poder de decisión en la estructura laboral. En este sentido-y tal como aseveramos en acápites anteriores-en este enfoque observamos que las actividades de reporteo de noticias están orientadas por una estructura burocrática, que se deriva de la organización de las fuentes de información que proveen la mayor cantidad de imput a los medios, o sea, las estructuras burocráticas informativas dependen de fuentes oficiales. Por lo que un punto interesante a considerar es lo que Schudson llama «la organización social del trabajo informativo», es el de la relación entre los reporteros y los funcionarios o relación entre los representantes de las «burocracias informativas» y los de las «burocracias gubernamentales» (Schudson, 1989: 271). En este aspecto es relevante el planteamiento de Tuchman al considerar las rutinas diarias que emplean las organizaciones informativas para obtener datos que se vuelvan noticiables. Sugiere que:

[...] el incremento de la competición por los ingresos por la publicidad alcanzados por la circulación condujo a los medios a desarrollar fuentes de información centralizadas, al modo de cordones umbilicales que conectan la redacción con sus fuentes de subsistencia (Tuchman: 1978: 32).

En consecuencia, una de las grandes condicionantes para la objetividad, la imparcialidad y la pluralidad de voces de los distintos actores sociales es en concreto esta agenda de trabajo de los medios, en donde los periodistas de modo rutinario - $\mathrm{y}$ por condicionamientos económicos como lo advierte Tuchman (1978) - acuden a fuentes fijas que les proporcionan insumos para construir la noticia, insumo informacional que en la mayoría de los casos resulta una versión oficial o propagandística de los hechos.

A modo de ejemplificación: esta dependencia excesiva de las fuentes oficiales en la cobertura noticiosa del "conflicto mapuche» en la prensa chilena es abordada por Del Valle (2005), quien intenta comprender el proceso de producción 
del discurso público massmediático en torno a lo mapuche, en el caso de la prensa regional y local, especialmente mediante el uso y abuso que se hace de las fuentes, entendidas aquí como discursos autónomos que constituyen ciertas reglas de interpretación de los discursos massmediáticos. La hipótesis validada en este estudio dice relación con que se observa una construcción pública del "conflicto mapuche», a partir de ciertas fuentes oficiales (vinculadas al Gobierno, la Policía, los tribunales de justicia y los partidos políticos) que le atribuyen un carácter político, para invisibilizar el carácter étnico y sociocultural asociado a las demandas y reivindicaciones indígenas. En cuyo caso se entenderá que a partir de esas fuentes particulares y locales, lo que se hará en el resto de la prensa nacional e internacional — mediante la agencia que concentra la información a nivel local (ORBE) - será una re-producción discursiva.

Se hace más evidente aún la influencia de las fuentes oficiales en su vinculación con los medios al constatar la creciente preponderancia que han adquirido los llamados Gabinetes de Prensa en las rutinas periodísticas. En razón de su importancia, damos cabida en este trabajo a un estudio realizado en el año 1995 por Txema Ramírez en que analiza la incidencia real que los Gabinetes de Prensa tienen en el quehacer diario de los periodistas, en especial en la prensa española, objeto de estudio. Conceptualiza Ramírez a los Gabinetes de Prensa como «aquellas fuentes activas, organizadas y habitualmente estables de información que cubren las necesidades informativas de aquellas organizaciones del ámbito cultural, social, político o económico que aspiran a tener influencia ante la opinión pública» (Ramírez, 1995:1). Parte esta autora de la premisa que los gabinetes cercanos al poder político y económico hacen más fuertes a las fuentes informativas oficiales y más débiles a las no oficiales. En su citado trabajo, Ramírez (1995) arriba a las siguientes conclusiones: a) en el actual sistema informativo, los Gabinetes de Prensa cumplen una función necesaria, positiva y socialmente aceptada. b) la normalización de las relaciones entre políticos y periodistas y la proliferación de Gabinetes de Prensa son fenómenos paralelos. Cuanto más profesional es el trabajo de un gabinete, las relaciones entre políticos y periodistas se encauzan, cada vez más, por la vía de la normalidad. c) Todos los Gabinetes de Prensa no reciben el mismo trato por parte de los medios informativos: los Gabinetes institucionales presentan una alta influencia, a pesar de su bajo nivel de credibilidad. En cambio, los Gabinetes de los movimientos sociales y las ONG, tienen escaso peso para los medios, no obstante su máxima credibilidad. d) los Gabinetes al servirse de las rutinas condicionan la producción periodística, ahondando cada vez más en el hábito y disminuyendo el trabajo creativo de los periodistas.

\section{Conclusiones}

El racismo — aquí concebido como sistema de dominación y desigualdad social — se articula en prácticas sociales (discriminación, marginación y exclusión) y sociocogni- 
tivas (creencias, actitudes e ideologías prejuiciosas) y se prefigura en las rutinas profesionales institucionalizadas de los periodistas al modelar el conocimiento social acerca de las minorías étnicas. Esta práctica social de representación social del Otro se articula, modela y condiciona — desde una mirada de la sociología de los medios - por la vía de la utilización casi exclusiva de fuentes oficiales para el tratamiento noticioso de los temas étnicos, por el control de los temas, por medio del establecimiento de la «agenda setting» y la presentación de ciertos «encuadres interpretativos» (Teoría del framing).

En efecto, la construcción pública de los temas vinculados a las minorías étnicas se realiza a partir del uso mayoritario de fuentes gubernamentales, políticas y religiosas lo que propende, por un lado, a una invisibilización discursiva y social del aborigen o migrante y, por otro, a asociarlo a la disrupción del orden social. En lo que respecta al control de los temas étnicos se aprecia que la prensa los presenta en términos de "conflicto» social, ligado a la violencia y a la marginalidad respecto de las leyes y el orden público. Tematización que se plasma en la fijación por la prensa de la "agenda setting» (qué y cómo pensar en los temas étnicos) mediante el uso de "encuadres» (framing) noticiosos que hacen prevalecer una interpretación desde la conflictividad y la crítica hacia la cultura del migrante o de una minoría étnica aborigen.

Desde estas prácticas sociales que se reifican en las rutinas profesionales de los periodistas se materializan una serie de estrategias discursivas para la representación social negativa de la minoría étnica. Desde una óptica teórico-empírica hemos evidenciado el uso de estrategias lingüístico-discursivas relativas al discurso discriminatorio etno-racial como estrategias semántico-cognitivas de polarización entre Nosotros/Ellos y de Exclusión/Inclusión, como asimismo estrategias de intertextualidad que omiten la voz de los otros-étnicos; predicación, agencia y selección léxica para atribución de acciones negativas del exogrupo; selección y manipulación de los tópicos que reproducen una visión racista, en tanto que valora positivamente al endogrupo (la elite blanca) y negativamente al exogrupo (los indígenas o migrantes).

Finalmente, el estudio del racismo discursivo y su anclaje en el Análisis Crítico del Discurso y la sociología de los medios confirman nuestra hipótesis de trabajo y evidencian el carácter construido y discriminador del mensaje periodístico y que los medios - en consideración a los condicionamientos del contexto sociopolítico, las rutinas profesionales y los valores de los periodistas - seleccionan, omiten, enfatizan y negocian sus interpretaciones sobre lo étnico las que se enmarcan en el rol politico (Borrat, 1989) que le cabe a la prensa, inmersa en la ideología dominante y de la cual es su brazo cultural (Sáez, 2014). 


\section{Referencias bibliográficas}

Arrunátegui, C. (2010). El racismo en la prensa escrita peruana. En Discurso E Sociedad, Vol. 4 (3) 2010: 428-470. Recuperado de http://www.dissoc.org/ediciones/v04n03/ DS4\%283\%29Arrunategui.html

Barker, M. (1981). The New Racism. Londres: Junction Books.

Berger, P. y Luckmann, T. (1972). La construcción social de la realidad. Buenos Aires, Amorrortu.

Borrat, H. (1989). El periódico, actor político. Barcelona: Gustavo Gili.

Dearing, J. y Rogers, E. (1996), Communication Concepts 6: Agenda-setting. Thousand Oaks, CA: Sage.

Del Valle, C. (2005). Interculturalidad e intraculturalidad en el discurso de la prensa. Cobertura y tratamiento del discurso de las fuentes en el "conflicto indígena mapuche», desde el discurso político. En: Redes. Com. Revista de Estudios para el Desarrollo Social de la Comunicación, n.2: 83-111. Sevilla, Instituto Europeo de Comunicación y Desarrollo.

Dijk, T.A. van (2010). Análisis del discurso del racismo. En Crítica y Emancipación. Año II, número 3, pp. 65-94.

- (2006). Discurso de las élites y racismo institucional. En LARIO, M. (ed). Medios de comunicación e inmigración. Murcia, CAM-Obra Social. Convivir sin racismo: 15-34.

- (2005). Nuevo racismo y noticias. Un enfoque discursivo. En Mary Nash, Rosa Tello \& Núria Benach (Eds.), Inmigración, género y espacios urbanos. Los retos de la diversidad (pp. 33-55). Barcelona, Edicions Bellaterra.

- (1999). ¿Un estudio lingüístico de la ideología? En: Discurso, Cognición y Educación. Ensayos en Honor a Luis A. Gómez Macker. Giovanni Parodi Sweis, Editor. Ediciones Universitarias de la Universidad Católica de Valparaíso (Chile): 27-42.

- (1997). Racismo y análisis crítico de los medios. Barcelona: Paidós Ibérica.

- (1996). Análisis del discurso ideológico. Traducción: Ramón Alvarado. En: Versión (México D.F.), 6: 15-43.

- (1994). Discurso, poder y cognición social. Recuperado de http://www.geocities. com/estudiscurso/vandijk_dpcs.html

- (1990). La noticia como discurso: Comprensión, estructura y producción de la información. Barcelona, Paidós.

Entman, R. (1993). Representation and reality in the portrayal of blacks on network television news. En: Journalism Quarterly, 1994, 71 (3):509-520.

Fairclough, N. (2003). Intertuality and assumptions. En Analyzing Discourse. Textual analysis for social research. Routledge: New York, pp. 39-61.

- (1992). Discourse and Social Change. Oxford, Blackwell.

Fishman, M. (1980). Manujacturing the News, University of Texas Press, Austin. (Trad. cast.: La fabricación de la noticia, Buenos Aires, Tres Tiempos, 1983.)

Goffman, E. (1974). Frame analysis: An essay on the organization of experience. Cambrige, MA, Harvard University Press. 
Graves, J. (2001). Emperor's New Clothes. Biological Theories of Race at the Milennium. Rutgers University Press, New Brunswick, N.J., Londres.

Hernández, M. (1987). La sociología de la producción de noticias. Hacia un nuevo campo de investigación en México. En: Comunicación y Sociedad (DECS; Universidad de Guadalajara), núm. 30, mayo-agosto 1987: 209-242.

Hirsch, P. (1977). Ocupational, Organizational and Instititutional Models in Mass Media Research: Toward an Integrated Framework. En: Paul Hirsch, V. Miller and F.G. Kline (eds.) Strategies for Communication Research. Beverly Hills, CA: SAGE: 13-42.

Igartua, J. y Muñiz, C. (2014). Encuadres noticiosos e inmigración. Un análisis de la prensa y televisión españolas. Recuperado de http://www.ehu.es/zer/hemeroteca/pdfs/zer1606-igartua.pdf

López-Escobar, E. y Rey, F. (1996). La imagen de los candidatos: el segundo nivel de la agenda-setting». En: Comunicación y Sociedad, vol. IX, n. ${ }^{\text {os }} 1$ y 2: 39-65.

Lozano, José Carlos. (2007). Teoría e investigación de la comunicación de masas, Pearson Educación, México.

Martínez Lirola, M. (2013). Hacia una deconstrucción del racismo discursivo: el caso de los inmigrantes subsaharianos. En: Estudios Sociales, Año 45, Vol. XLI-Número 154 Enero-Marzo 2013: páginas 53-67.

- (2006). Una aproximación a la imagen del inmigrante en los textos multimodales de la prensa alicantina. ¿Estereotipos o realidad? En: Gómez Gil, C. (ed.) Otras miradas sobre la inmigración. Alicante, Universidad de Alicante: 151-174.

- y Crespo, E. (2010). Recursos léxicos y visuales en la representación periodística del inmigrante. En: Martínez, M. (ed.) Migraciones, discursos e ideologías en una sociedad globalizada. Claves para su mejor comprensión. Alicante: Colección Colectiva/8. Instituto Alicantino de Cultura Juan Gil-Albert: páginas 79-106.

- (2010). Hacia una deconstrucción de la ideología sobre la inmigración en la prensa gratuita a través de las palabras y las imágenes. En: Martínez, M. (ed.). Migraciones, discursos e idelogías en una sociedad globalizada. Claves para su mejor comprensión. Alicante, Colección Colectiva/8. Instituto Alicantino de Cultura Juan Gil-Albert: 143-160.

- (2008). Las relaciones entre las características lingüísticas y visuales de las noticias sobre inmigración en la prensa gratuita y la relación interpersonal con la audiencia. En: Discurso \& Sociedad, 2 (4): 799-815. Recuperado de http://www.dissoc.org

McCombs, M. y Shaw, D. (1972). The agenda-setting function of mass media». En: Public Opinion Quarterly, vol. 36, n. ${ }^{\circ}$ 2: 176-187.

-,López-Escobar, E. y Llamas, J. (2000). Setting the Agenda of Attributes in the 1996 Spanish General Election. En: Journal of Communication, 50 (2): 77-92.

Mignolo, W. (2004). Globalización, doble traducción e interculturalidad. En: deSigniS N. ${ }^{\circ}$ 6, Comunicación y conflictos interculturales: Barcelona, Editorial Gedisa. 21-33.

McQuail, D. (1994). Mass Communication Theory. An Introduction. Londres: SAGE.

Molina, G. (1989). The production of Mexican Commercial Television News: The Supremacy of Corporate Rationale. Thesis for the degree of Ph. D. on Mass Communications, Presented at the Centre for Mass Communication Research, University of Leicester. 
Montero, M.D. (1993). La información periodística y su influencia social. Bellaterra, Servei de Publicacions de la Universitat Autónoma de Barcelona.

Ramírez, T. (1995): La influencia de los gabinetes de prensa. Las rutinas periodísticas al servicio del poder. Recuperado de http://www.quadernsdigitals.net/datos/hemeroteca/ r_32/nr_453/a_6204/6204.pdf

Rodríguez Borges, R. (2010). Discurso xenófobo y fijación de agenda. Un estudio de caso en la prensa de canarias (España). En: Revista Latina de Comunicación Social, 65. La Laguna (Tenerife): Universidad de La Laguna, pp. 222 a 230.

Recuperado de http://www.revistalatinacs.org/10/art2/895_ULL/17_Rodrigo.html DOI: 10.4185/RLCS-65-2010-895-222-230

Sáez, J. (2015). Hacia una deconstrucción de la discriminación y el racismo discursivo referente a la cultura mapuche en la prensa chilena de mayor lectura. Bellaterra: Universidad Autónoma de Barcelona. Tesis Doctoral.

-,(2014). Racismo en la prensa chilena: deconstrucción de la frontera simbólica en la representación social del mapuche como el Otro.Revista Contextos, n. ${ }^{\circ} 32,121-134$. Recuperado de https://dialnet.unirioja.es/descarga/articulo/5427170.pdf

-,(2005). Tram(p)as de seducción y manipulación del imaginario social en los mass media: el caso del Diario La Nación. Revista F@ro, Año I/Tomo 1, Año 1.

Schudson, M. (1989). The Sociology of News Production. En: Media, Culture and Society, vol. 11: 263-282. Londres, SAGE.

Tankard, J.W. (2001). The empirical approach to the study of media framing. En: Reese, S.D. Gandy, O.H. y Grant, A.E. (Eds.) Framing public life. Perspectives on media and our understanding of the social world. Mahwah, NJ, Lawrence Erlbaum Associates: 95-106.

Tuchman, G.: (1978). Making news: a study in the construction of reality. Nueva Cork, Free Press. Traducción de Héctor Borrat: La producción de la noticia, estudio sobre la construcción de la realidad, Barcelona, Gustavo Gili.

Valera, L. (2016). El sesgo mediocéntrico del framing en España: una revision crítica de la aplicación de la teoría del encuadre en los estudios de comunicación. ZER: Revista de Estudios de Comunicación, Vol. 21-Núm. 11, 13-31. Recuperado de http://www.ehu. eus/ojs/index.php/Zer/article/view/17259/15060

Veron, E. (1983). Construir el acontecimiento. Barcelona, Gedisa.

Wieviorka, M. (2002). El racismo. Una introducción. La Paz, Plural Editores.

Winter, J. y Eyal, C. (1981). Agenda-setting for a civil rights issue. En: Public Opinion Quarterly, n. ${ }^{\circ}$ 45: 376-383.

Whitney, D.C. (1982) Mass Communicator Studies: Similarity, Difference and Level of Analysis en J.S. Ettema and D.C. Whitney (eds.) lndividuals in Mass Media Organizations: Creativity and Constraint. Beverly Hills, CA: SAGE, pp. 241-254.

Wodak, R. y Meyer, M. (2003). Métodos de análisis crítico del discurso. Barcelona, Editorial Gedisa.

Wolf, M. (1987). La investigación de la comunicación de masas. Crítica y perspectivas. Barcelona: Paidós. 